\title{
Papers
}

\section{Randomised controlled trial of laparoscopic versus open mesh repair for inguinal hernia: outcome and cost}

James Wellwood, Mark J Sculpher, David Stoker, Graham J Nicholls, Cathy Geddes, Anne Whitehead, Rameet Singh, David Spiegelhalter

\begin{abstract}
Objective: To compare tension-free open mesh hernioplasty under local anaesthetic with transabdominal preperitoneal laparoscopic hernia repair under general anaesthetic.

Design: A randomised controlled trial of 403 patients with inguinal hernias.

Setting: Two acute general hospitals in London between May 1995 and December 1996.

Subjects: 400 patients with a diagnosis of groin hernia, 200 in each group.

Main outcome measures: Time until discharge, postoperative pain, and complications; patients' perceived health (SF-36), duration of convalescence, and patients' satisfaction with surgery; and health service costs.

Results: More patients in the open group (96\%) than in the laparoscopic group (89\%) were discharged on the same day as the operation $\left(\chi^{2}=6.7 ; 1 \mathrm{df} ; \mathrm{P}=0.01\right)$. Although pain scores were lower in the open group while the effect of the local anaesthetic persisted (proportional odds ratio at 2 hours 3.5 (2.3 to 5.1)), scores after open repair were significantly higher for each day of the first week $(0.5$ ( 0.3 to 0.7$)$ on day 7$)$ and during the second week (0.7 (0.5 to 0.9$))$. At 1 month there was a greater improvement (or less deterioration) in mean SF-36 scores over baseline in the laparoscopic group compared with the open group on seven of eight dimensions, reaching significance on five. For every activity considered the median time until return to normal was significantly shorter for the laparoscopic group. Patients randomised to laparoscopic repair were more satisfied with surgery at 1 month and 3 months after surgery. The mean cost per patient of laparoscopic repair was $£ 335$ (95\% confidence interval £228 to £441) more than the cost of open repair.

Conclusion: This study confirms that laparoscopic hernia repair has considerable short term clinical advantages after discharge compared with open mesh hernioplasty, although it was more expensive.
\end{abstract}

\section{Introduction}

The use of preformed mesh to repair inguinal hernias is gaining wide acceptance ${ }^{1}$ and is replacing repairs by suturing such as the Shouldice repair ${ }^{2}$ or Maloney darn. ${ }^{3}$
There is, however, disagreement about the relative merits of laparoscopic mesh placement by using three small abdominal incisions compared with placement of mesh by using an open approach through a standard groin incision. Using a randomised controlled trial we compared these two methods of inguinal hernia repair in terms of their clinical and patient based outcomes and health service costs. This paper details outcomes and cost results up to 3 months after surgery.

\section{Patients and methods}

\section{Trial design}

Figure 1 illustrates the design of the trial. All patients with an inguinal hernia seen at Whipps Cross or the North Middlesex Hospital between May 1995 and December 1996 were considered for entry into the study. Patients who were unfit for general anaesthesia, had psychological complaints, were pregnant, were

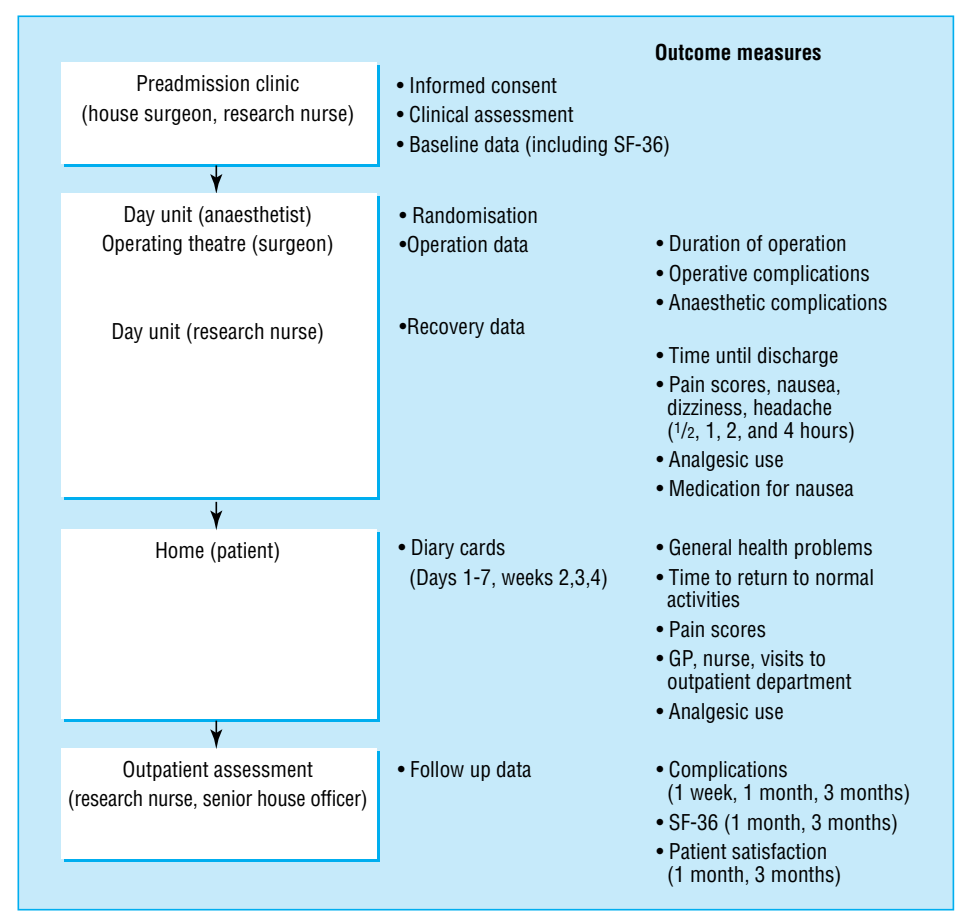

Fig 1 Design of trial and outcome measures of laparoscopic $v$ open repair of inguinal hernia

\section{Whipps Cross Hospital, London E11 1NR \\ James Wellwood, consultant surgeon Cathy Geddes, research nurse \\ Rameet Singh, associate anaesthetic specialist \\ Health Economics Research Group, Brunel University, Uxbridge, Middlesex UB8 3PH Mark J Sculpher, research fellow}

BMJ 1998;317:103-10 
North Middlesex Hospital, London N18 1QX

David Stoker, consultant surgeon

Medical and Pharmaceutical Statistics Research Unit, University of Reading, PO Box 240 , Reading RG6 6FN

Graham J Nicholls, research fellow Anne Whitehead, deputy director

MRC Biostatistics Unit, Institute of Public Health, Cambridge CB2 2SR David Spiegelhalter, senior statistician

Correspondence to: Mr Wellwood under 18 years of age, or had a poor understanding of English were excluded. Written informed consent was obtained at clinics before admission. Patients were admitted to the day case unit on the morning of their operation and were assessed by the anaesthetist. A randomisation schedule was prepared by one person (DS) in balanced blocks randomly chosen to be of length 4 or 6 . To delay allocation to the latest possible time, allocations were placed in consecutive opaque envelopes and the seal broken in the anaesthetic room immediately before surgery. The surgeon recorded operative details on a standardised form.

Patients were allowed to leave hospital when they were able to dress themselves and had passed urine. Those requiring inpatient treatment were transferred to a main ward. Patients were asked to complete a diary card daily on the first 7 days after surgery and at the end of the 2nd, 3rd, and 4th weeks. Follow up data were collected at outpatient visits 1 week, 1 month, and 3 months after surgery by the research nurse and the surgical senior house officer. Further review of patients continues at 1 and 5 years. In common with most surgical trials it was not feasible for clinical personnel to remain blind to the allocated surgery group.

Two consultant surgeons and five senior surgical registrars took part, all of whom were already practising the open mesh technique. Senior surgical registrars were permitted to operate in the trial after assisting in 10 laparoscopic procedures and being supervised in a further five, demonstrating their competence.

\section{Surgical techniques}

The trial protocol required patients having laparoscopic repair to receive general anaesthesia and those undergoing open repair to have local anaesthesia.

Laparoscopic repair-Laparoscopic repair was by a standard three port technique, which has been reported previously. ${ }^{45}$ A $15 \times 10 \mathrm{~cm}$ polypropylene mesh (Prolene, Ethicon, Edinburgh) was placed in a preperitoneal pocket and was stapled in position with the EMS multifeed staple gun (Ethicon, Edinburgh). The peritoneum was replaced to exclude the mesh from the peritoneal cavity and stapled in position. Bilateral laparoscopic repair was performed with either two separate meshes as described above or a single $28 \times 10 \mathrm{~cm}$ mesh stretching across the pelvic floor.

Open repair-For the open technique the mesh was placed and secured after the method of Lichtenstein. ${ }^{6}$ Early results indicated a higher than expected incidence of purulent discharge from wounds in patients having an open repair, and the last $82(41 \%)$ patients were given a single injection of antibiotic during the operation.

\section{Outcome measures}

Figure 1 shows the outcome data collected at each time point. Careful follow up of patients ensured the identification of the more common surgical complications of the procedures. Patients indicated their level of pain at various time points by using integer scores of 0 (no pain) to 10 (unbearable pain). A range of measures of function and wellbeing from the perspective of the patient was assessed in the trial. The first was the SF-36 health survey questionnaire, ${ }^{7-11}$ which consists of eight multi-item dimensions, each of which generates a score of between 0 and 100; higher scores indicate higher levels of perceived health. The duration of convalescence was assessed by using the diary card: patients recorded whether they felt well enough to undertake usual activities around the house (for example, washing and dressing), carry out social activities, and drive a car. For the first 7 days after the operation patients recorded their ability to move freely around the house and walk short distances. At 3 months patients who were in employment were asked when they had returned to work. Patients' level of satisfaction was assessed by asking how satisfied they were with their treatment and whether they would recommend their operation to a friend or relative with a hernia.

\section{Cost estimation}

The cost analysis was undertaken from the perspective of the health service. Measures of use of resources were divided into those that were expected to vary by patient within each arm of the trial (stochastic) and those that could reasonably be assumed to be constant within each arm (fixed). Stochastic resource data were collected prospectively and included time in theatre, the number of disposable stapling guns used as part of the laparoscopic procedure, and implications of complications on resources.

Fixed resource data were based on observation of clinical practice and discussion with staff about practice at the participating hospitals. Resource items included staff present, most consumables, and all equipment. Fixed consumables included stitches, dressings, mesh prostheses, and, for the laparoscopic procedure, disposable scissors. The laparoscopic repair involved a basic set of reusable instruments, including trocars and cannulas, forceps, and a Verres needle as well as other equipment such as a camera, video, and laparoscope. The basic open set included various forceps, scissors, and retractors. A diathermy machine was used in both procedures.

The monetary valuation of resource use was undertaken by attaching unit costs at 1996-7 prices. Staff costs were based on midpoint salaries and include employers' costs. Given the low acquisition cost of oral analgesics, only intramuscular analgesics and antiemetic drugs were costed. The costs of all drugs were according to manufacturers' list prices including value added tax (VAT) ${ }^{12}$; consumables were costed on a similar basis. Equipment costs were calculated according to manufacturers' list prices (including VAT) translated into an equivalent annual $\operatorname{cost}^{13}$ by using a $6 \%$ discount rate ${ }^{14}$ and estimates of each item's useful life expectancy. These costs were divided by estimated annual throughput to give costs per patient, and estimates of cleaning and sterilisation costs were added.

In addition to the theatre costs that can be directly allocated to individual patients, theatre overheads, which include the costs of power and cleaning as estimated by one of the participating hospitals, were included. The costs per hour on the day care unit, on the surgical ward (both including nursing), and per visit for the outpatient clinic were based on a similar calculation. The costs of community based health services such as general practitioner visits were based on published estimates ${ }^{15}$ uprated for health service inflation. ${ }^{16}$ 


\section{Statistical methods}

The trial was originally designed to last 18 months and enrol 340 patients. By using data from a previous study $^{5}$ we estimated this sample size to provide $80 \%$ power at the two sided 5\% significance level to detect a feasible and important change of $26 \%$ in analgesic use and a 19\% change in days until normal activity.

An analysis of variance was performed on the time taken for surgery after logarithmic transformation to allow for skewness; the comparison between groups was based on the ratio of duration of laparoscopic versus open repair. Data from patients who provided at least half of the data from the diary card were included in the analysis of return to each activity with missing data replaced by the mean of the available data. Cox's proportional hazards modelling ${ }^{17}$ was used to analyse the time back to each activity and the time until discharge from hospital with comparisons presented as hazard ratios for open versus laparoscopic repair For the preceding time analyses, adjustment was made for age, sex, total body surface area, American Society of Anesthesiologists (ASA) score, unilateral or bilateral hernia, and new or recurrent hernia. We used $\chi^{2}$ tests for postoperative complications and use of medication. The proportional odds model for ordered categorical data $^{18}$ was used to analyse the pain scores; the comparison is presented as a proportional odds ratio of less pain after open repair compared with laparoscopic repair. The change from baseline of the SF-36 scores at 1 and 3 months after the operation and the patient satisfaction data were analysed with the Mann-Whitney U test.

For patients for whom data on postoperative complications were missing, the total cost is underestimated. By treating such patients as censored observations and by using Kaplan-Meier estimation, the mean (SE) cost can be obtained. ${ }^{19-21}$

With sensitivity analysis, we carried out two alternative analyses to assess the effect on differential cost of a "mainly disposable consumables" policy and a "mainly reusable equipment" policy on the basis of plausible clinical practice. In addition, we used sensitivity analysis to assess the importance of variation in the unit cost of stay on the day case unit and on a surgical ward.

Each estimate of difference between the groups is presented with a $95 \%$ confidence interval. An intention to treat analysis was adopted, including all patients who actually had an inguinal hernia and for whom the operation began. No interim analyses were planned or conducted.

\section{Results}

\section{Characteristics of patients}

Because of excellent recruitment and availability of resources the trial was conducted over a 20 month period and enrolled 403 patients, 19\% more than originally planned. A further 148 patients were screened, of whom 59 refused to take part and 89 were considered unsuitable. Three patients were excluded from the analysis (in one no hernia was found, one had a femoral hernia, one withdrew after randomisation but before surgery). Of the 400 remaining patients, 200 in each group, 268 were treated at Whipps Cross Hospital and 132 were treated at the North Middlesex Hospital. Patients in the two surgery groups were com- parable (table 1) with the exception that more patients undergoing laparoscopic repair (32) had hypertension than in the open group (16). Of the 255 patients who were in paid employment, 59 had a sedentary job, 109 had an active job, and 87 had a heavy job. The two groups were comparable for both the physical activity of employment and hours of employment.

\section{Surgical procedures}

The two consultants performed 152 and 130 of the operations, and 118 were performed by senior registrars. There was no major imbalance in the proportion of laparoscopic procedures nor of bilateral hernia repairs performed by the consultants or trainees. The median duration of surgery ("knife to skin" to "last stitch") was the same for the two procedures both for unilateral repairs (45 minutes) and bilateral repairs (65 minutes). After adjustment for covariates, there was no difference in the duration of surgery for open and laparoscopic repair of unilateral hernias (no time reduction; $-6 \%$ to $5 \%$ ). Bilateral hernia repairs, however, were performed significantly more quickly laparoscopically (16\% time reduction; 3\% to $27 \%$ ). One consultant performed laparoscopic significantly faster than open repair, the second consultant took a similar time for each, and senior registrars were significantly faster performing the open repair. When the total time from entering the anaesthetic room until entering the recovery room was analysed, medians of 15 and 10 minutes were added to the operation time for patients in the laparoscopic and open repair groups, respectively.

\section{Intraoperative and anaesthetic complications}

There were few intraoperative complications in either group. In the laparoscopic repair group one patient required conversion to an open procedure because of dense adhesions and two patients required catheterisation during the operation to empty a full bladder. In the open repair group four patients required administration of general anaesthesia because of intolerance of the procedure under local anaesthesia, one patient with bilateral hernias declined to have the second side repaired, the vas deferens was inadvertently divided in one patient, and nerves identified either as genito-

Table 1 Descriptive data for patients' characteristics, employment, and hernia according to allocated method of surgery. Values are numbers of patients unless stated otherwise

\begin{tabular}{lcc} 
Detail & Laparoscopic repair $(\mathbf{n}=\mathbf{2 0 0})$ & Open repair $(\mathbf{n}=\mathbf{2 0 0})$ \\
\hline Men & 193 & 190 \\
\hline Median (range) age (years) & $52.5(19-83)$ & $51.5(19-80)$ \\
\hline Median (range) surface area $\left(\mathrm{m}^{2}\right)$ & $1.88(1.48-2.24)$ & $1.86(1.39-2.42)$ \\
\hline American Society of Anesthesiologists score 1,2 & 193 & 193 \\
\hline Taking regular analgesia or NSAID & 28 & 27 \\
\hline Urinary symptoms & 14 & 17 \\
\hline Previous lower abdominal surgery & 57 & 56 \\
\hline Hypertension & 32 & 16 \\
\hline Employed & 96 & 99 \\
\hline Self employed & 31 & 29 \\
\hline Unemployed, retired, housework & 72 & 72 \\
\hline Hernias: & & 176 \\
\hline Unilateral & 177 & 24 \\
\hline Bilateral & 23 & 181 \\
\hline New & 179 & 19 \\
\hline Recurrent & 21 & \\
\hline
\end{tabular}

NSAID=non-steroidal anti-inflammatory drug. 


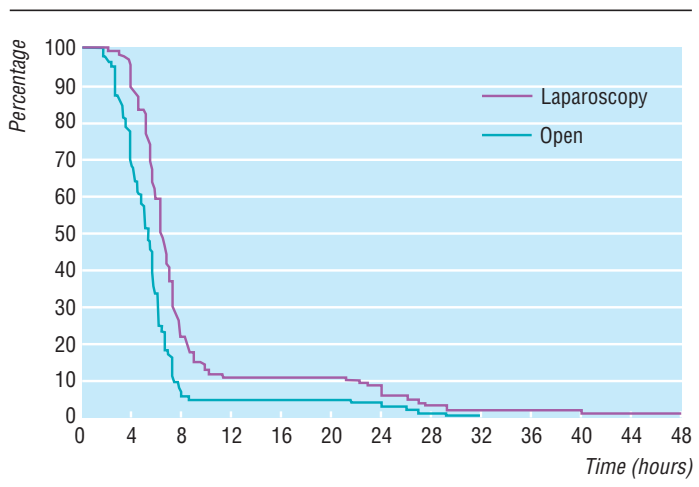

Fig 2 Proportion of patients not yet discharged from hospital over time. Median times (hours) to discharge 6.00 for laparoscopic patients and 5.17 for open patients. Hazard ratio of discharge for open relative to laparoscopic 2.17 (1.73 to 2.72 )

femoral or ileoinguinal were divided in eight patients. No patient in either group sustained visceral injury.

\section{Length of stay}

Significantly more patients in the open repair group (191) than in the laparoscopic repair group (177) went home on the day of the operation $\left(\chi^{2}=6.7 ; 1 \mathrm{df}\right.$; $\mathrm{P}=0.01)$. Of the 23 inpatient transfers after laparoscopic repair, 14 were unplanned; six of these were due to difficulty in passing urine while the others were due to a combination of pain, apprehension, and general malaise. There was only one unplanned admission in the open repair group. All nine patients from the open group who were transferred as inpatients and 19 out of 23 patients from the laparoscopy group were discharged on the next day (fig 2). Two patients in the laparoscopy group were discharged after 2 days and two further patients were discharged after 3 and 5 days. Cox's proportional hazards model fitted to the length of stay, with additional adjustment made for whether or not it was planned for the patient to be kept in hospital, showed a significant increase in the time until discharge for the laparoscopy group compared with the open group $\left(\chi^{2}=44.7 ; 1 \mathrm{df} ; \mathrm{P}<0.01\right)$.

\section{Recovery on the day care unit (first 4 hours)}

Nausea, dizziness, and headache were more common after the laparoscopic operation, which necessitates a general anaesthetic. The number of patients who felt sick, dizzy, or had a headache at the time points $1 / 2,1$, and 2 hours after laparoscopic repair was 58/198, $50 / 198$, and $45 / 198$, respectively, compared with $17 / 198,12 / 197$, and $10 / 194$, respectively, for the open group (smallest $\chi^{2}=25.1 ; 1 \mathrm{df} ; \mathrm{P}<0.01$ ). There were also significantly more patients in the laparoscopic group compared with the open repair group with these symptoms at 4 hours, although 151 patients $(38 \%)$ had missing data, mostly because they had been discharged. Six patients in the laparoscopic group required medication for nausea.

The pain scores obtained at 1/2, 1, 2, and 4 hours after surgery showed that the number of patients after laparoscopic repair who had no pain was 73/198, $67 / 198,74 / 199$, and $62 / 142$, respectively, compared with $157 / 199,154 / 197,129 / 194$, and $60 / 108$ for the open group. Proportional odds modelling of the visual pain scores at 1/2, 1, and 2 hours after surgery showed significantly more pain for the laparoscopic group than the open group (smallest ( 2 hours) $\chi^{2}=39.8$; $1 \mathrm{df}$; $\mathrm{P}<0.01$; odds ratio (2 hours) $3.46 ; 2.33$ to 5.13 ). The proportional odds model fitted to the 142 laparoscopic group and 108 open patients with scores available at 4 hours after surgery also revealed less pain for the open group than the laparoscopy group $\left(\chi^{2}=6.6 ; 1 \mathrm{df}\right.$; $\mathrm{P}=0.01 ; 1.87 ; 1.15$ to 3.02$)$. No analgesia was required on the day unit in 167 open repair patients compared with 132 laparoscopic repair patients $\left(\chi^{2}=16.2 ; 1 \mathrm{df}\right.$; $\mathrm{P}<0.01)$

\section{Patient diary cards}

Diary cards for the first week (days 1-7) were completed by 395 patients (197 laparoscopy, 198 open), and 379 patients (188 laparoscopy, 191 open) completed the diary cards for each of weeks 2,3 , and 4 .

Proportional odds modelling of the visual pain scores revealed significantly less pain felt after laparoscopic repair than after open repair on each of the first 7 days after surgery (smallest (day 7) $\chi^{2}=14.3 ; 1 \mathrm{df}$; $\mathrm{P}<0.01$; odds ratio (day 7) $0.49 ; 0.33$ to 0.71 ) and also during week $2\left(\chi^{2}=5.0 ; 1 \mathrm{df} ; \mathrm{P}=0.03 ; 0.66 ; 0.45\right.$ to 0.95$)$. This is consistent with less use of pain relief observed in the laparoscopic repair group during the first 2 weeks. There were no significant differences in the pain scores between the two groups at weeks 3 and 4 (table 2).

\section{Postoperative complications}

Data on postoperative complications 1 week after surgery were available for all patients, whereas the numbers of patients for whom data were available at 1 month and 3 months were 383 (190 laparoscopy, 193 open) and 358 (182 laparoscopic, 176 open), respectively.

During the first 3 months after surgery there were significantly more patients in the open repair group who experienced wound infection, persisting groin or thigh pain, genital swelling, local numbness, and constipation (table 3). There was also a higher incidence of bruising or groin swelling, or both, in the open repair group.

Table 2 Pain scores in patients after hernia repair by open or laparoscopic surgery. Values are proportions of patients

\begin{tabular}{|c|c|c|c|}
\hline Pain score* & Laparoscopic repair & Open repair & $\begin{array}{l}\text { P value for overall } \\
\text { difference }\end{array}$ \\
\hline \multicolumn{4}{|l|}{ Day 1} \\
\hline 0 & $8 / 197$ & $5 / 198$ & \multirow{3}{*}{$<0.01$} \\
\hline $1-5$ & $135 / 197$ & $66 / 198$ & \\
\hline $6-10$ & $54 / 197$ & 127/198 & \\
\hline \multicolumn{4}{|l|}{ Day 4} \\
\hline 0 & $21 / 197$ & 8/198 & \multirow{3}{*}{$<0.01$} \\
\hline $1-5$ & $153 / 197$ & $138 / 198$ & \\
\hline 6-10 & $23 / 197$ & $52 / 198$ & \\
\hline \multicolumn{4}{|l|}{ Day 7} \\
\hline 0 & $36 / 196$ & $24 / 196$ & \multirow{3}{*}{$<0.01$} \\
\hline $1-5$ & $153 / 196$ & 157/196 & \\
\hline 6-10 & $7 / 196$ & $15 / 196$ & \\
\hline \multicolumn{4}{|l|}{ Week 2} \\
\hline 0 & $44 / 188$ & $40 / 192$ & \multirow{3}{*}{0.03} \\
\hline $1-5$ & $136 / 188$ & $135 / 192$ & \\
\hline $6-10$ & $8 / 188$ & $17 / 192$ & \\
\hline \multicolumn{4}{|l|}{ Week 4} \\
\hline 0 & $60 / 164$ & $69 / 174$ & \multirow{3}{*}{0.51} \\
\hline $1-5$ & $96 / 164$ & $99 / 174$ & \\
\hline $6-10$ & $8 / 164$ & $6 / 174$ & \\
\hline
\end{tabular}

${ }^{*} 0=$ no pain, $10=$ unbearable pain 
Table 3 Numbers (percentages) of patients with postoperative complications occurring within 3 months after surgery for hernia repair according to allocated method of surgery

\begin{tabular}{|c|c|c|c|c|}
\hline Complication & $\begin{array}{l}\text { Laparoscopic } \\
\text { repair } \\
\left(\mathrm{n}=200^{*}\right)\end{array}$ & $\begin{array}{c}\text { Open repair } \\
\left(n=200^{*}\right)\end{array}$ & $\begin{array}{c}\chi^{2} \\
(1 \mathrm{df})\end{array}$ & $\begin{array}{c}P \\
\text { value }\end{array}$ \\
\hline Wound infection & $6(3)$ & $19(11)$ & 7.3 & $<0.01$ \\
\hline Groin or thigh paint & $104(55)$ & $133(71)$ & 10.0 & $<0.01$ \\
\hline $\begin{array}{l}\text { Bruising or severe groin } \\
\text { swelling }\end{array}$ & $107(58)$ & $117(62)$ & 0.6 & 0.46 \\
\hline Genital swelling & $49(27)$ & $76(41)$ & 8.2 & $<0.01$ \\
\hline Local numbness & $3(2)$ & $37(21)$ & 32.2 & $<0.01$ \\
\hline Urinary retention & $12(7)$ & $5(3)$ & 2.9 & 0.09 \\
\hline Constipation & $32(18)$ & $56(31)$ & 8.8 & $<0.01$ \\
\hline Testicular atrophy & 0 & $2(1)$ & NA & $0.24 \ddagger$ \\
\hline Death (within 30 days) & 0 & $1(0.5)$ & NA & $1.00 \ddagger$ \\
\hline Intestinal obstruction & 0 & 0 & NA & NA \\
\hline Recurrence or port site hernia & 0 & 0 & NA & NA \\
\hline Readmission & $3(2) \S$ & $6(3)$ ๆ & NA & $0.50 \ddagger$ \\
\hline
\end{tabular}

NA=not applicable.

${ }^{*}$ Data incomplete for small numbers of patients.

†Pain persisting at postoperative visit at 1 week, 1 month, or 3 months. fFisher's exact test.

$\S 0$ ne with haematuria, one with severe pain, one with hydrocele.

१One with haematoma (required surgical drainage), four with sepsis (one required surgical drainage), one who fell (on day 1).

More patients in the laparoscopic group, however, suffered from urinary retention. Almost all wound infection (23/25), urinary retention (16/17), and constipation $(87 / 88)$ was detected within the first 7 days after surgery. Eleven open patients and two laparoscopic patients required antibiotic treatment for wound infection. There were 45 patients in each surgery group with groin or thigh pain lasting 1 month, whereas at 3 months there were 27 laparoscopic patients and 40 open patients in whom this pain persisted. Although there were more open patients than laparoscopy patients who experienced both bruising or groin swelling and genital swelling during the first 3 months after surgery, there were more laparoscopy patients with these complications persisting at both 1 month (groin swelling in 33 laparoscopy, 19 open; genital swelling in 17 laparoscopy, 16 open) and 3 months (groin swelling in 12 laparoscopy, two open; genital swelling in 11 laparoscopic, five open).

The number of patients with local numbness persisting at 1 and 3 months was 24 (one laparoscopic, 23 open) and 23 (one laparoscopic, 22 open), respectively. There were three laparoscopy patients and six open patients who required readmission to hospital. One patient in whom the hernia sac was transected rather than withdrawn during laparoscopic repair developed a hydrocele which later required excision. One patient died at home of myocardial infarction 19 days after open repair. From the general health data collected as part of the diary card there were significantly more laparoscopy patients (11) than open patients (1) who suffered from a sore throat $\left(\chi^{2}=8.7 ; 1\right.$ $\mathrm{df} ; \mathrm{P}<0.01)$ during the first week after surgery.

\section{Patient based outcomes}

The SF-36 questionnaire was completed by 392 patients at baseline (197 laparoscopic, 195 open), 369 at 1 month (184 laparoscopic, 185 open), and 353 at 3 months (179 laparoscopic, 174 open). At 1 month after surgery there was greater improvement (or less deterioration) in mean scores over baseline in the laparoscopic group compared with the open group on each of the dimensions of the instrument except general health (table 4). The differences observed were significant for five dimensions. At 3 months after surgery there were greater improvements in mean scores over baseline in the laparoscopic group for all items except general health, but none of these differences reached significance.

On the basis of diary card data the median time at which patients returned to every activity was shorter for the laparoscopic group, and most of these differences were significant (table 5). As an example, the percentage of patients who had not returned to their usual activities around the house during the first month after surgery is shown in figure 3 . The

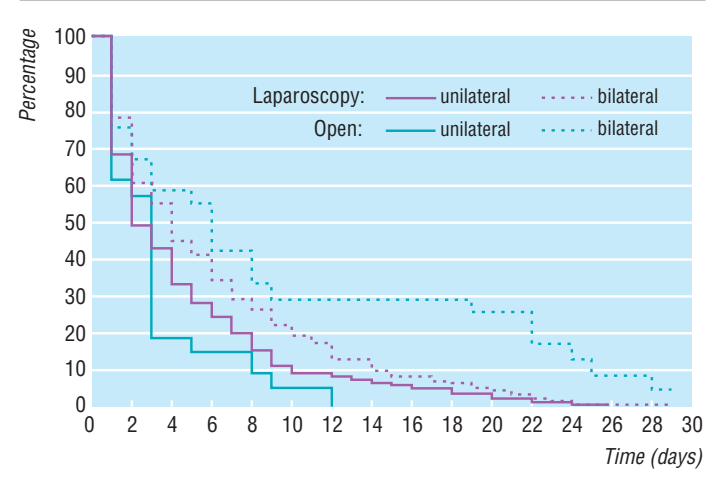

Fig 3 Survival curve showing proportion of patients not yet returned to usual activities around house over time after hernia repair

Table 4 Mean SF-36 scores at baseline and changes from baseline at 1 and 3 months. Higher scores equal better perceived health. Values in parentheses are numbers of patients for whom data were available

\begin{tabular}{|c|c|c|c|c|c|c|c|c|}
\hline \multirow[b]{3}{*}{ Dimension } & & & \multicolumn{6}{|c|}{ Mean difference from baseline score } \\
\hline & \multicolumn{2}{|c|}{ Mean at baseline } & \multicolumn{3}{|c|}{ At 1 month } & \multicolumn{3}{|c|}{ At 3 months } \\
\hline & $\begin{array}{l}\text { Laparoscopic } \\
\text { repair }\end{array}$ & Open repair & $\begin{array}{l}\text { Laparoscopic } \\
\text { repair }\end{array}$ & Open repair & $P$ value & $\begin{array}{c}\text { Laparoscopic } \\
\text { repair }\end{array}$ & Open repair & $P$ value \\
\hline Physical functioning & $74.9(194)$ & $79.3(195)$ & $2.2(178)$ & $-0.7(179)$ & 0.16 & $10.2(168)$ & $6.1(165)$ & 0.09 \\
\hline Role-physical $^{*}$ & $65.8(192)$ & $68.3(194)$ & $-17.8(174)$ & $-29.6(176)$ & 0.03 & $19.1(167)$ & $16.0(165)$ & 0.27 \\
\hline Bodily pain & $61.5(197)$ & $64.5(195)$ & $-0.5(180)$ & $-10.0(180)$ & $<0.01$ & $21.9(176)$ & $18.4(168)$ & 0.18 \\
\hline General health & 74.1 (195) & $71.8(195)$ & $2.4(177)$ & $2.8(181)$ & 0.89 & $5.1(174)$ & $6.1(168)$ & 0.84 \\
\hline Vitality & $62.2(197)$ & $64.6(195)$ & $2.2(179)$ & $-3.6(181)$ & $<0.01$ & $9.6(176)$ & $7.7(169)$ & 0.46 \\
\hline Social functioning & 83.8 (197) & $84.0(195)$ & $-4.2(181)$ & $-11.1(181)$ & 0.01 & $6.6(176)$ & $5.9(169)$ & 0.41 \\
\hline Role-emotional† & 78.3 (192) & 80.5 (194) & $-2.5(174)$ & $-12.0(177)$ & 0.11 & $10.0(166)$ & $6.6(164)$ & 0.35 \\
\hline Mental health & 73.9 (197) & 74.9 (195) & $5.4(180)$ & $1.7(178)$ & 0.01 & $8.1(176)$ & $6.8(168)$ & 0.60 \\
\hline
\end{tabular}

${ }^{\star}$ Role limitations due to physical problems.

†Role limitations due to emotional problems. 
Table 5 Duration of convalescence as measured by time back to various activities in patients undergoing hernia repair according to allocated method of surgery. Values in parentheses are numbers of patients for whom data were available

\begin{tabular}{|c|c|c|c|}
\hline \multirow[b]{2}{*}{ Activity } & \multicolumn{2}{|c|}{ Median days until resumption } & \multirow[b]{2}{*}{$\begin{array}{l}\text { Hazard ratio }(95 \% \mathrm{CI}) \text { for } \\
\text { open } v \text { laparoscopic repair }\end{array}$} \\
\hline & $\begin{array}{l}\text { Laparoscopic } \\
\text { repair }\end{array}$ & $\begin{array}{l}\text { Open } \\
\text { repair }\end{array}$ & \\
\hline \multicolumn{4}{|l|}{ Usual activities around houset: } \\
\hline Unilateral & $2.0(160)$ & $4.0(164)$ & $0.78(0.60$ to 0.99$)$ \\
\hline Bilateral & $3.0(20)$ & $6.0(24)$ & $0.26(0.13$ to 0.54$)$ \\
\hline Moving freely about house & $1.0(197)$ & $3.0(199)$ & $0.52(0.40$ to 0.67$)$ \\
\hline Walking short distances & $3.0(197)$ & $4.0(199)$ & 0.51 (0.40 to 0.65$)$ \\
\hline \multicolumn{4}{|l|}{ Social activitiest: } \\
\hline Unilateral & $5.0(159)$ & $8.0(163)$ & $0.66(0.52$ to 0.84$)$ \\
\hline Bilateral & $5.0(20)$ & $13.5(24)$ & $0.23(0.12$ to 0.45$)$ \\
\hline Driving car & $7.0(131)$ & $8.5(132)$ & 0.73 (0.56 to 0.95$)$ \\
\hline \multicolumn{4}{|l|}{ Back to work (taking it easy)ł: } \\
\hline Active or heavy & $17.0(95)$ & $21.0(86)$ & 0.87 (0.63 to 1.20$)$ \\
\hline Sedentary & $10.0(27)$ & $14.0(32)$ & $0.41(0.23$ to 0.75$)$ \\
\hline \multicolumn{4}{|l|}{ Back to work (fully)ł: } \\
\hline Active or heavy & $21.0(95)$ & $26.0(86)$ & 0.89 (0.65 to 1.23$)$ \\
\hline Sedentary & $11.0(27)$ & $18.0(32)$ & $0.43(0.24$ to 0.79$)$ \\
\hline
\end{tabular}

${ }^{*}$ After adjustment for range of predefined covariates (see text).

†Significant interaction between type of hernia and surgical procedure.

$\ddagger$ Significant interaction between physical activity of employment and surgial procedure.

Table 6 Patients' satisfaction with surgery. Values are numbers (percentages) of patients

\begin{tabular}{lcccccc} 
& \multicolumn{2}{c}{ One month after surgery } & & \multicolumn{2}{c}{ Three months after surgery } \\
\cline { 2 - 3 } \cline { 6 - 6 } Response & $\begin{array}{c}\text { Laparoscopic } \\
\text { repair }(\mathbf{n = 1 7 9 )}\end{array}$ & $\begin{array}{c}\text { Open repair } \\
(\mathbf{n = 1 8 4 )}\end{array}$ & & $\begin{array}{c}\text { Laparoscopic } \\
\text { repair }(\mathbf{n = 1 7 7})\end{array}$ & $\begin{array}{c}\text { Open repair } \\
(\mathbf{n}=\mathbf{1 7 3})\end{array}$ \\
\hline Very satisfied & $150(83.8)$ & $129(70.1)$ & & $155(87.6)$ & $129(74.6)$ \\
\hline Moderately satisfied & $26(14.5)$ & $44(23.9)$ & & $17(9.6)$ & $38(22.0)$ \\
\hline Dissatisfied & $2(1.1)$ & $8(4.4)$ & & $2(1.1)$ & $5(2.9)$ \\
\hline Very dissatisfied & $1(0.6)$ & $3(1.6)$ & & $3(1.7)$ & $1(0.6)$ \\
\hline
\end{tabular}

difference between the two groups was more pronounced for patients with bilateral hernias, which was also a characteristic of time to return to normal social activities. Although patients in the laparoscopy group generally returned to work both "taking it easy" and "full blast" earlier than the open group, the differences observed were significant only for those patients with an occupation described as sedentary.

Patients randomised to laparoscopic repair were more satisfied with surgery at both 1 month and 3 months $(\mathrm{P}<0.01)$ after surgery (table 6$)$. At 1 month, 171 patients in the laparoscopy group said they would recommend the procedure that they had undergone to a friend or relative with a hernia compared with 163 open patients $(\mathrm{P}=0.02)$. The results were similar at 3 months: $168 / 175$ and $151 / 172$, respectively $(\mathrm{P}<0.01)$.

Costs

Table 7 details use of patients' resources together with unit costs. The major differences between the two groups in terms of use of resources were the use of expensive consumables and more costly equipment as part of the laparoscopic procedure.

Table 8 shows the mean costs of the two procedures obtained after 3 months' follow up. There were 50 patients (24 laparoscopic, 26 open) who had a censored total cost because of incomplete data on postoperative complications. Overall, the mean cost per patient of laparoscopic repair was $£ 335$ (95\% confidence interval $£ 228$ to £441) more than the cost of open repair. This cost difference is driven by the higher cost of theatre consumables (mean difference £281
(£271 to £291) and equipment (£31; £30 to £31). These differences are partly offset by the higher cost of postoperative complications in the open group (mean difference $£ 68$ ( $-£ 105$ to $£ 241)$ ). Ninety per cent of open patients had a 3 month follow up cost less than $£ 519.64$ compared with $£ 875.94$ for the same proportion of laparoscopic patients (figure 4). For a small proportion of patients in both groups, however, the costs were far greater than these amounts because of complications.

Sensitivity analysis showed that if, as part of the laparoscopic procedure, reusable scissors were used and instead of stapling the mesh into place it was stitched the mean difference in cost would fall to $£ 75$ ( $-£ 31$ to $£ 181$ ). If a "largely disposable" policy were followed in which, in addition to the disposables used for laparoscopic repair in the base-case analysis, equipment such as trocars were also disposable, the mean cost difference would increase to $£ 523$ ( $£ 419$ to $£ 626$ ). Plausible changes in the cost of an hour on the day case unit and the cost of a day on a ward had a very small effect on the differential cost of the two procedures.

\section{Discussion}

This study compares the outcomes in patients treated on a day care unit by the most common method of laparoscopic repair (transabdominal, preperitoneal) with general anaesthesia or with a standard open mesh hernioplasty as described by Lichtenstein, ${ }^{6}$ with local anaesthesia. We have shown that for unilateral hernia repairs the laparoscopic operation does not necessarily take longer to perform than the open operation and could be quicker for bilateral hernia repairs. Laparoscopic repair is, however, technically more demanding and surgeons need specific training in the technique.

There were few operative complications in either surgical group, although, in common with earlier studies, ${ }^{52-28}$ this trial was not powered to detect differences in serious but rare complications. Local neurovascular complications occurred mainly in the open repair group, and this is reflected in the increased incidence of postoperative numbness and pain in addition to the two cases of testicular atrophy. The risk of injury to nerves and vessels constitutes a valid

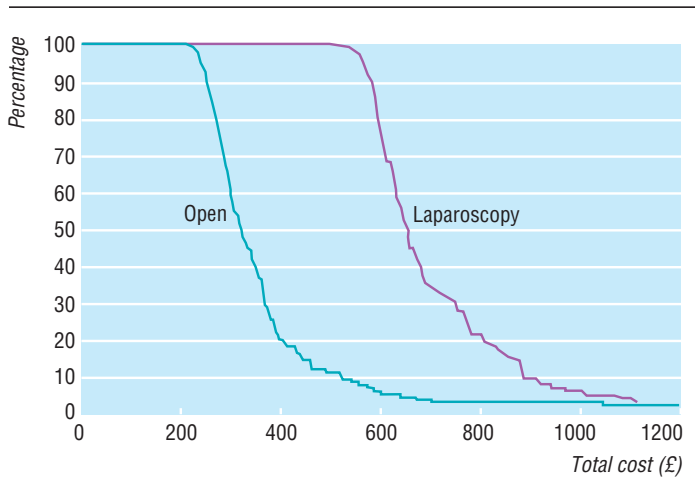

Fig 4 Survival curve of total cost showing proportion of patients who have consumed resources valued over specific costs. Patients for whom postoperative cost data at 1 or 3 months were missing have been censored. Three open and three laparoscopy patients had costs over $£ 1200$ 
Table 7 Consumption of key resources until 3 months' follow up and their unit costs. Figures are numbers (percentages) of patients unless stated otherwise

\begin{tabular}{|c|c|c|c|}
\hline \multirow[b]{2}{*}{ Item of resource } & \multicolumn{2}{|c|}{ Resource consumption } & \multirow[b]{2}{*}{ Unit cost } \\
\hline & Laparoscopic repair & Open repair & \\
\hline \multicolumn{4}{|l|}{ Theatre resources } \\
\hline Mean (SD) time in anaesthetic room (mins) ${ }^{*}$ & $16.14(4.90)$ & $11.41(5.24)$ & Staff (per min): $£ 0.86$; overheads (per min): $£ 0.20$ \\
\hline Mean (SD) duration of operation (mins) & $46.59(16.80)$ & $46.83(15.70)$ & Staff (per min): £1.92; overheads (per min): $£ 0.20$ \\
\hline Mean (SD) time in recovery room (mins) & $30.00(0.00)$ & $10.40(2.81)$ & Staff (per min): $£ 0.20$; overheads (per min): $£ 0.20$ \\
\hline \multicolumn{4}{|l|}{ Operatives drugs } \\
\hline Prophylactic antibiotics & $2(1.0)$ & $82(41.0)$ & Mean per patient: $£ 5.23 \dagger$ \\
\hline Local anaesthetic & 0 & $200(100.0)$ & Mean per patient: £6.57† \\
\hline General anaesthetic & $200(100.0)$ & $4(2.0)$ & Mean per patient: £14.88† \\
\hline \multicolumn{4}{|l|}{ Consumables } \\
\hline One prosthetic mesh & $177(88.5)$ & $176(88.0)$ & Per item: $£ 23.77$ \\
\hline Two prosthetic meshes & $23(11.5)$ & $24(12.0)$ & Per item: $£ 23.77$ \\
\hline Mean (SD) No of disposable stapling guns & $1.17(0.41)$ & 0 & Per item: $£ 157.65$ \\
\hline Disposable scissors & 199 (99.5)‡ & 0 & Per item: $£ 105.75$ \\
\hline Other laparoscopic consumables & 199 (99.5)‡ & 0 & Per patient: £2.64 \\
\hline Other open consumables & $1(0.5) \ddagger$ & $200(100.0)$ & Per patient: £9.81 \\
\hline \multicolumn{4}{|l|}{ Equipment } \\
\hline Laparoscopic equipment & $200(100.0)$ & 0 & Per patient: £42.92; equipment sterilisation: £18.80 \\
\hline Open equipment & $1(0.5) \ddagger$ & $200(100.0)$ & Per patient: £5.40; sterilisation: $£ 25.70$ \\
\hline \multicolumn{4}{|l|}{ Operative complications with resource use } \\
\hline Need for catheterisation & $2(1.0)$ & 0 & Per item: $£ 2.60$ \\
\hline \multicolumn{4}{|l|}{ Stay in hospital } \\
\hline Day cases & $177(88.5)$ & $191(95.5)$ & \\
\hline Mean (SD) length of stay as daycase (hours) & $6.08(1.56)$ & $4.99(1.47)$ & Per hour: $£ 4.71$ \\
\hline Inpatient transfers & 23 (11.5) & $9(4.5)$ & \\
\hline Mean (SD) length of inpatient stay (days) & $1.35(0.93)$ & $1.11(0.13)$ & Per day: $£ 190.00$ \\
\hline \multicolumn{4}{|l|}{ Subsequent resource use } \\
\hline Mean (SD) No of visits to GP & $0.61(1.00)$ & $0.65(1.02)$ & Per visit: $£ 16.21$ \\
\hline Mean (SD) No of visits by nurse & $0.01(0.14)$ & $0.34(1.83)$ & Per visit: £17.21 \\
\hline Mean (SD) No of outpatient visits & $1.95(0.54)$ & $2.01(0.55)$ & Per visit: $£ 47.00$ \\
\hline Hospital readmissions & $3(1.5)$ & $6(3.0)$ & \\
\hline Mean (SD) length of readmissions (days) & $6.33(3.51)$ & $6.17(7.99)$ & Per day: $£ 190.00$ \\
\hline Postoperative complications§ & $12(6.0)$ & $19(9.5)$ & Mean per patient: $£ 33.33 \dagger$ \\
\hline \multicolumn{4}{|l|}{ Postoperative drug use: } \\
\hline Intramuscular analgesia & $18(9.0)$ & $2(1.0)$ & Mean per patient: £2.48† \\
\hline Antiemetics & $6(3.0)$ & 0 & Mean per patient: $£ 0.37 \dagger$ \\
\hline
\end{tabular}

$\mathrm{GP}=$ general practitioner. *Also includes time at end of operation before patient was removed to recovery room. $†$ Based on resource use of average patient. $\ddagger 0$ ne patient randomised to laparoscopic repair was converted to open repair. §Does not include any hospital stay.

indication for laparoscopic repair of recurrent hernias as the old wound and its associated scarring is avoided. No recurrent hernias have been found after 3 months' follow up.

Many open repair patients were discharged before the effect of the local anaesthesia had worn off, and they consequently experienced significantly less pain in the day care unit. On the morning after surgery and for the next 2 weeks, however, open repair patients had significantly more pain than laparoscopic repair patients. The observed reduction in postoperative pain after laparoscopic repair is probably due to the small incisions used and the smaller amount of dissection required for this repair and has been reported previously. ${ }^{5}$

The use of general anaesthesia may account for the lower proportion of laparoscopic patients who went home on the same day as surgery. ${ }^{29}$ Wound infection was defined as any purulent wound discharge, however asymptomatic. Four patients in the open group were readmitted for wound infection, although some purulent wound discharge occurred in $11 \%$ of open patients. This may seem high but close postoperative surveillance ensured accurate detection, and there is evidence that surgeons and hospital records may seriously underestimate the true incidence of clinically minor wound infections after hernia repair. ${ }^{30}$

This paper shows that neither form of repair is unequivocally more cost effective. In terms of effectiveness all the patient based outcomes and pain after the day of operation favoured laparoscopic repair or were

Table 8 Total costs $(£)$ per patient of two forms of hernia repair

\begin{tabular}{|c|c|c|c|}
\hline \multirow[b]{2}{*}{ Cost component } & \multicolumn{2}{|c|}{ Mean (SE) cost per patient } & \multirow{2}{*}{$\begin{array}{c}\text { Mean cost difference } \\
(95 \% \text { CI) for laparoscopic } v \\
\text { open repair }\end{array}$} \\
\hline & Laparoscopic repair & Open repair & \\
\hline Anaesthetics & $15.05(0.06)$ & $6.69(0.19)$ & 8.36 (7.97 to 8.75$)$ \\
\hline Prophylactic antibiotics & $0.05(0.04)$ & $2.15(0.18)$ & $-2.09(-2.46$ to -1.73$)$ \\
\hline \multicolumn{4}{|l|}{ Theatre costs: } \\
\hline Staff and overheads & $127.87(2.59)$ & $115.53(2.44)$ & 12.34 (5.37 to 19.31) \\
\hline Consumables & $318.85(5.16)$ & $37.63(0.78)$ & 281.22 (271.00 to 291.45$)$ \\
\hline Equipment & $61.88(0.16)$ & $31.10(0.00)$ & 30.78 (30.47 to 31.08 ) \\
\hline Complications & $0.03(0.02)$ & $0.00(0.00)$ & $0.03(-0.01$ to 0.06$)$ \\
\hline Ward and day case costs & $54.93(6.66)$ & $31.88(2.81)$ & 23.04 (8.87 to 37.22 ) \\
\hline GP and nurse visits & $10.06(1.17)$ & $16.31(2.65)$ & $-6.25(-11.92$ to -0.58$)$ \\
\hline Outpatient visits & 91.65 (1.79) & $94.24(1.84)$ & -2.59 (-7.67 to 2.44$)$ \\
\hline Postoperative complications & $72.13(38.11)$ & $140.39(79.50)$ & $-68.26(-241.06$ to 104.54$)$ \\
\hline Postoperative drugs & $0.23(0.08)$ & $0.03(0.02)$ & $0.20(0.05$ to 0.35$)$ \\
\hline Total & 746.87 (35.19) & 412.27 (41.14) & $334.60(228.49$ to 440.71$)$ \\
\hline
\end{tabular}

$\mathrm{GP}=$ general practitioner. 
Key messages

- In the 4 hours after surgery laparoscopic hernia repair with general anaesthesia causes more pain than open repair with local anaesthesia (mainly because of the anaesthesia used) and necessitates longer stay in hospital.

Laparoscopic hernia repair, however, causes less pain than open hernia repair during the first 2 weeks after discharge

- Laparoscopic hernia repair results in fewer episodes of wound infection, persistent local pain, genital swelling, numbness, and constipation than open repair. Urinary disturbances are more common after laparoscopic than after open repair

- Patients' perception of health 1 month after the operation (assessed with the SF-36) and satisfaction with treatment is superior for laparoscopic patients who also have a shorter period of convalescence after surgery

- The health service cost of day case laparoscopic repair is $£ 335$ more than the cost of open mesh hernioplasty performed on a day case basis

equivalent. This greater effectiveness, however, comes at a cost. On the basis of use of resources in the trial centres, laparoscopic repair has a mean cost $£ 335$ higher than the cost of open repair, with the additional cost reflecting the higher cost of surgical equipment and consumables with laparoscopic repair. In particular, the disposable scissors and stapling gun alone cost at least $£ 263$ per patient in the trial centres. Although they may not generate the same outcomes as seen in this trial, greater use of reusable equipment could reduce the mean difference in cost to as little as $£ 75$ ( $-£ 31$ to $£ 181$ ).

Further analysis of outcomes and costs will be undertaken on data from 1 and 5 year follow up.

The authors are grateful to Denise Walters and Jim Fong for their help in cost estimation. All views and any errors are the responsibility of the authors alone.

Contributors: JW initiated the study and research funding application, helped to design all aspects of the study, supervised and performed surgical procedures, interpreted results relating to clinical outcomes, and helped to write the paper. MJS contributed to the research funding application, helped to design the study (in particular patients based outcomes and costs), guided and participated in data analysis (particularly of patients based outcomes and costs), and helped to write the paper. DS participated in the initiation of the study and research funding application, performed surgical procedures, interpreted results relating to clinical outcomes, and helped to write the paper. GJN participated in the analysis of all data and helped to write the paper. CG helped to design the data collection instruments, collected and coded data, assisted the process of data analysis, and edited the paper. AW guided all data analysis (particularly methodological issues) and edited the paper. RS helped to initiate the study and design data collection instruments, interpreted results relating to anaesthesia, and edited the paper. DS participated in the initiation of the study and research funding application, designed the randomisation schedule, helped to design other aspects of the study, and edited the paper.

Funding: This research was funded by the Medical Research Council. The Health Economics Research Group receives funding through the Department of Health Policy Research Programme.

Conflicts of interest: MJS has acted as consultant to Ethicon but not relating to products associated with hernia repair.
1 Amid PK, Shulman AG, Lichtenstein IL. Critical scrutiny of the open "tension free" hernioplasty. Am J Surg 1993;165:369-71.

2 Devlin HB, Gillen PHA, Waxman BP, MacNay RA. Short stay surgery for inguinal hernia: experience of the Shouldice operation 1970-82. BrJ Surg 1986:73:123-4.

3 Maloney GE, Gill WG, Barclay RC. Operations for hernia-technique of nylon darn. Lancet 1948;ii:45-8.

4 Corbitt JB. Transabdominal preperitoneal herniorrhaphy. Surg Laparosc Endosc 1993;3:328-32.

5 Stoker DL, Spiegelhalter DJ, Wellwood JM. Laparoscopic versus open inguinal hernia repair: randomised prospective trial. Lancet $1994 ; 343: 1243-5$.

6 Lichtenstein IL, Shulman AG, Amid PK, Monttlor MM. The tension-free hernioplasty. Am J Surg 1989;157:188-93.

7 Jenkinson C, Coulter A, Wright L. Short form 36 (SF-36) health survey questionnaire: normative data for adults of working age. BMJ 1993;306:1437-40

8 Garratt AM, Ruta DA, Abdalla MI, Buckingham JK, Russell IT. The SF-36 health survey questionnaire: an outcome measure suitable for routine use within the NHS? BMJ 1993;306:1440-4.

9 Jenkinson C, Wright L, Coulter A. Criterion validity and reliability of the SF-36 in a population sample. Qual Life Res 1994;3:7-12.

10 Ruta DA, Abdalla MI, Garratt AM, Coutts A, Russell IT. SF-36 health survey questionnaire. I. Reliability in two patient based studies. Qual Health Care 1994;3:180-5.

11 Garratt AM, Ruta DA, Abdalla MI, Russell IT. SF-36 health survey questionnaire. II. Responsiveness to changes in health status in four common clinical conditions. Qual Health Care 1994;3:186-92.

12 British Medical Association and the Royal Pharmaceutical Society of Great Britain. British National Formulary. London: British Medical Association and the Roval Pharmaceutical Society of Great Britain, 1996 (No 32 , September).

13 Drummond MF, O'Brien BJ, Stoddart GL, Torrance GW. Methods for the economic evaluation of health care programmes. New York: Oxford University Press, 1997.

14 HM Treasury. Economic appraisal in central government: a technical guide for government departments. London: HMSO, 1991.

15 Netten A, Dennett J. Unit costs of health and social care. Canterbury: PSSRU, University of Kent, 1996.

16 NHS Executive. Health service cost index. Leeds: Department of Health, 1996.

17 Cox DR. Regression models and life-tables. J Roy Stat Soc B 1972;34:187-

18 McCullagh P. Regression models for ordinal data. J Roy Stat Soc B 1980;43:109-42.

19 Fenn P, McGuire A, Backhouse M, Jones D. Modelling programme costs in economic evaluation. J Health Economics 1996;15:115-25.

20 Kaplan E, Meier P. Non-parametric estimation from incomplete observations. J Am Stat Assoc 1958;53:457-81.

21 SAS. SAS/STAT user's guide. Version 6. Cary, North Carolina: SAS Institute, 1989.

22 Maddern GJ, Rudkin G, Bessell JR, Devitt P, Ponte L. A comparison of laparoscopic and open hernia repair as a day surgical procedure. Surg Fndosc 1994:8:1404-8.

23 Lawrence K, McWhinnie D, Goodwin A, Doll H, Gordon A, Gray A, et al. Randomised controlled trial of laparoscopic versus open repair of inguinal hernia: early results. BMJ 1995;311:981-5.

24 Leibl B, Daubler P, Schwarz J, Ulrich M, Bittner R. Standardised laparoscopic (TAPP) versus Shouldice repair of inguinal hernia. Results from a prospective randomised and controlled trial. Chirurg 1995;66:895-8.

25 Barkun JS, Wexler MJ, Hinchey EJ, Thibeault D, Meakins JL. Laparoscopic versus open inguinal herniorrhaphy: preliminary results of a randomised controlled trial. Surgery 1995;118:703-10.

26 Vogt DM, Curet MJ, Pitcher DE, Martin DT, Zucker KA. Preliminary results of a prospective randomised trial of laparoscopic only versus conventional inguinal herniorrhaphy. Am J Surg 1995;169:84-90.

27 Hauters P, Meunier D, Urgyan S, Jouret JC, Janssen P, Nys JM. Prospective randomised study comparing laparoscopy and Shouldice technique in the treatment of unilateral inguinal hernia. Ann Chir 1996;50:776-81.

28 Wright DM, Kennedy A, Baxter JN, Fullarton GM, Fife LM, Sunderland GT, et al. Early outcome after open versus extraperitoneal endoscopic tension-free hernioplasty: a randomized clinical trial. Surgery 1996;119:552-7.

29 Teasdale C, McCrum A, Williams NB, Horton RE. A randomised controlled trial to compare local with general anaesthesia for short-stay inguinal hernia repair. Ann Roy Coll Surg Engl 1982;64:238-42.

30 Bailey IS, Karran SE, Toyn K, Brough P, Ranaboldo C, Karran SJ Community surveillance of complications after hernia repair. BMJ 1992;304:469-71.

(Accepted 27 March 1998)

\section{Endpiece \\ Alternative definitions}

Meekness: Uncommon patience in planning a revenge which is worth while.

Ambrose Bierce, The Cynic's Word Book (1906), subsequently titled The Devil's Dictionary 